\title{
استشراف المستقبل في عهد ما بعد الثورات العربية
}

\section{هيئة التحرير}

ليس مـ السهـل أن تخلو كلمـة التحرير في هذا العـدد مـن بحلة إسلامية المعرفة مـن

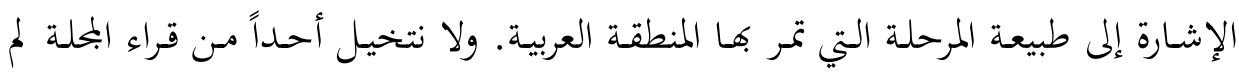

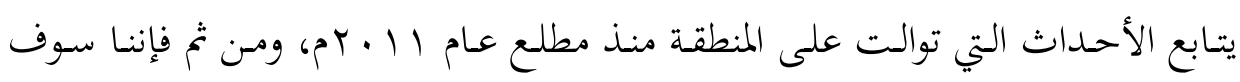
نتجاوز عن الحمديث عن وصف ما حمدث وتفسيره، لنقصره على إشارات مقتضبة إلى المستقبل القريب في الشهور وربما السنوات القليلة القادمة، وسوف تكون هذه الإشارات

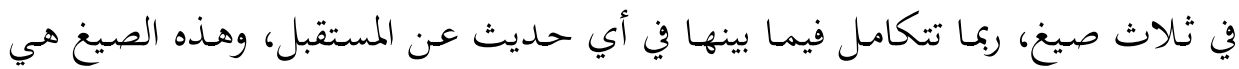
تساؤلات وآمال واحتمالات.

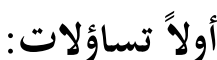

ثمة تساؤلات تتماهى مع احتمالات المستقبل الذي سيكون نتيجة لأحداث الثورات

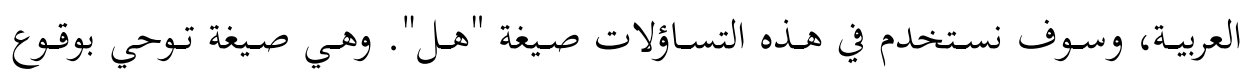

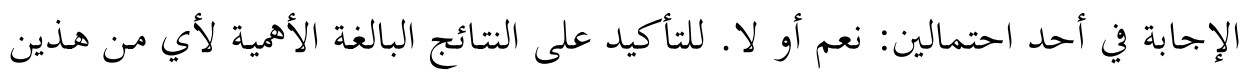
الاحتمالين. ومن هذه التساؤلات:

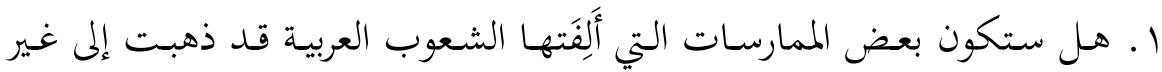

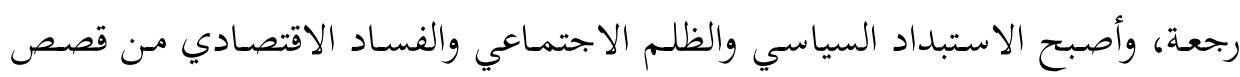
الماضي؟ r. هل سيتوقف السياسيون في بلادناعن قول شيء وفعل شيء آخر يناقض ما قالوه، بعد أن أصبح الكذب صفة ملازمة للسياسيين؟

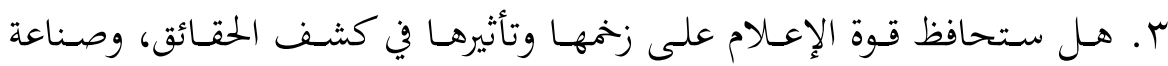


ـ. هـل ستسـير جهود الإصـالح في ابتحاهـات إيجابيـة، وينتقل دعـاة الإصـالح مـن الوعي السالب إلى المشاركة في تحمل المسؤولية؟

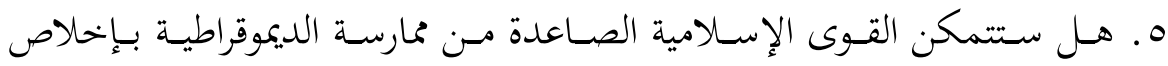

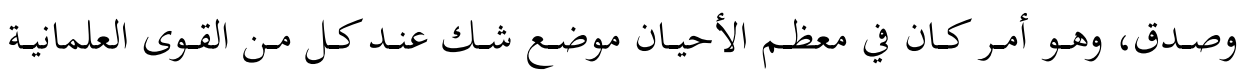

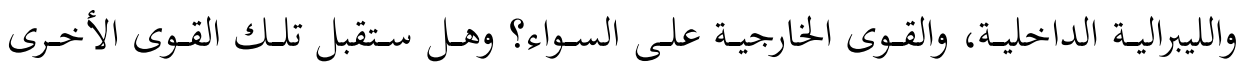

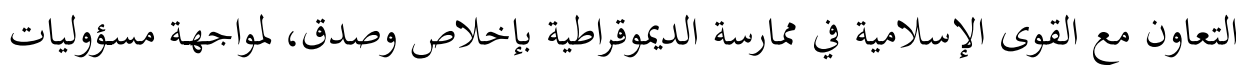

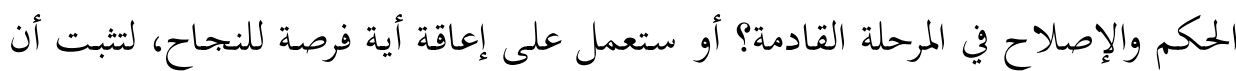

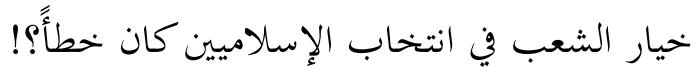

\section{ثانياً: آمال وطموحات}

ثمة آمال في الإصلاح تلوّّن الصورة المنشودة التي تأمُل الشعوب أن تتحقق في المرحلة القادمة بوصفها نتيجة لهذه الثورات العربية المتلاحقة. ومن الأمثلة على هذه الآمال: 1. آمال في إصلاح فكري وثقافي يعيد للمجتمع العربي هويته الإسلامية، ويبني له

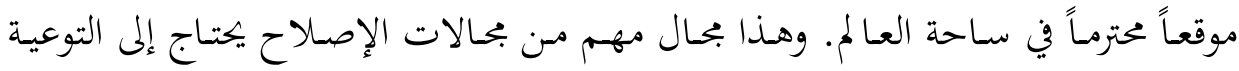

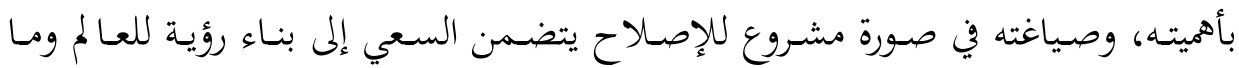
ينبثق عنها من نظرية معرفية ومنهجية في التفكير والبحث والسلوك.

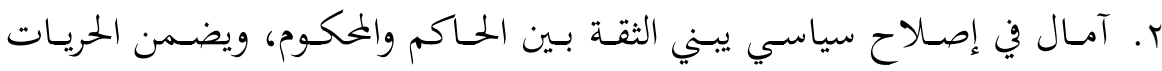
الأساسية والعامة، ويقيم التوازن بين السلطات المختلفة للقيام بأدوارها بإخلاص وفي وفاعلية،

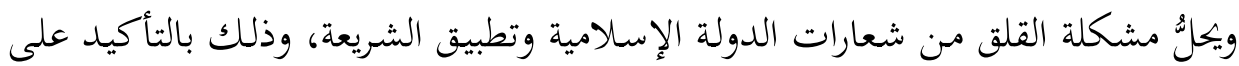

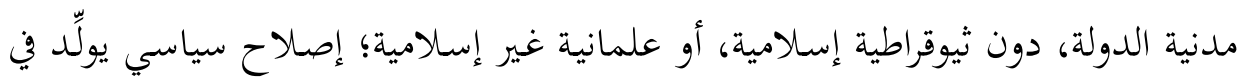

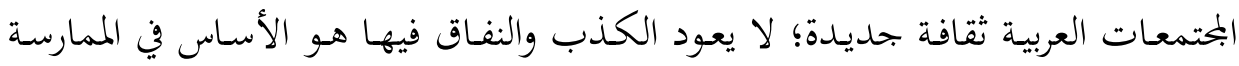

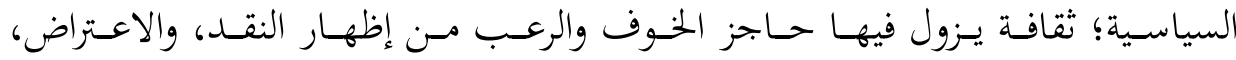

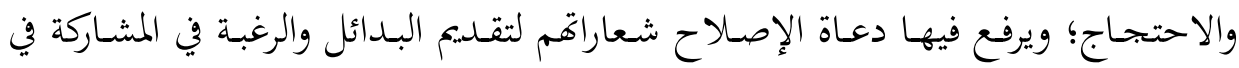

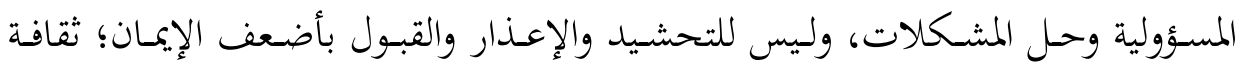




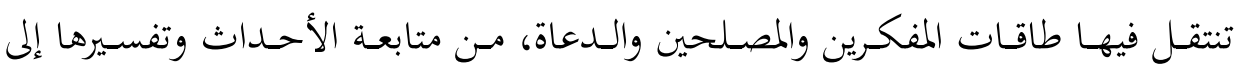

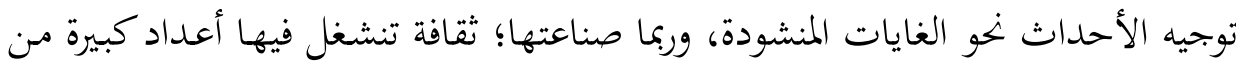

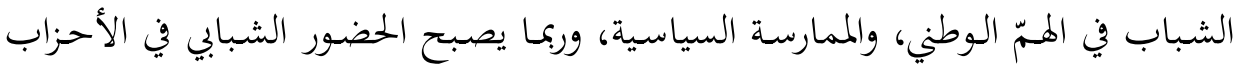

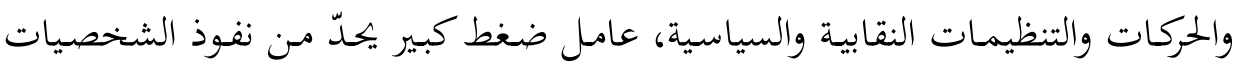
التقليدية التي تتصف بالتقدم في السنّ.

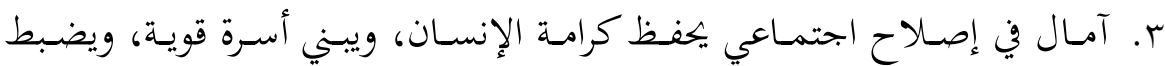

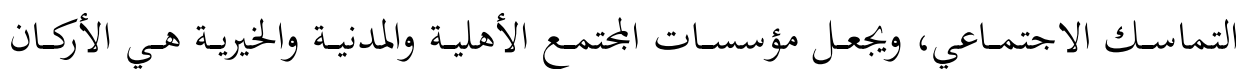

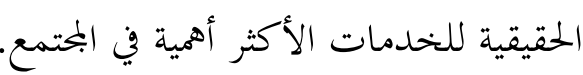
ع. آمال في إصلاح إعلامي يطور الوعي السياسي والممارسات الشريفة الشيفة، التي تنهي

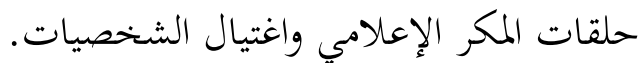

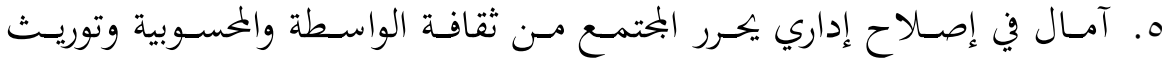

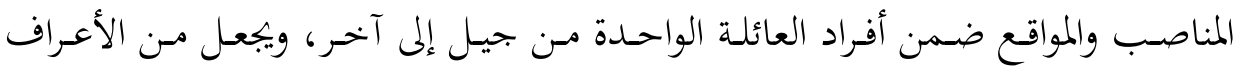

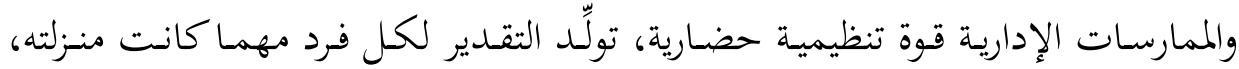
والاحترام للآراء الجمعية التي ترشد طرق التخاذ القرارات وإنفاذها بيسر وفاعلية.

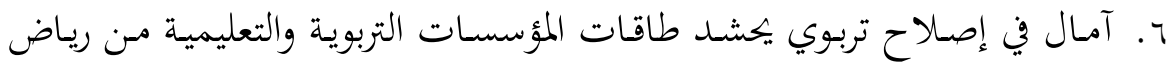

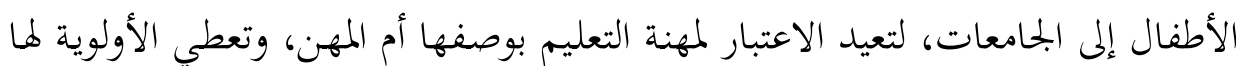

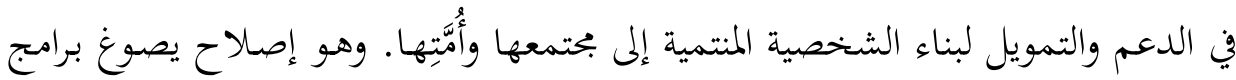

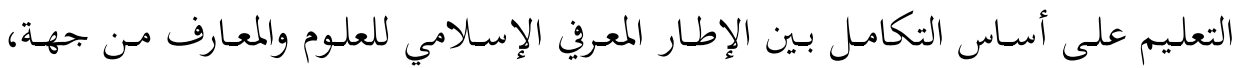

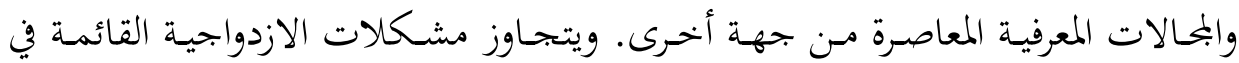

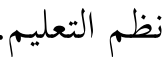
V. آمال في إصـالاح اقتصـادي يعيد بنـاء الفلسفة والفكر الاقتصـادي والممارسة

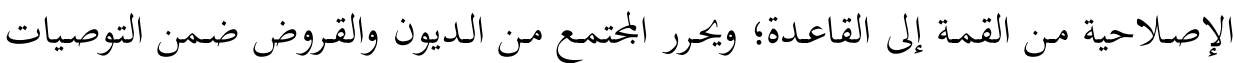

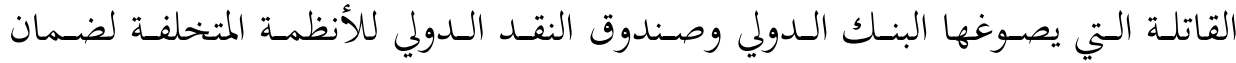

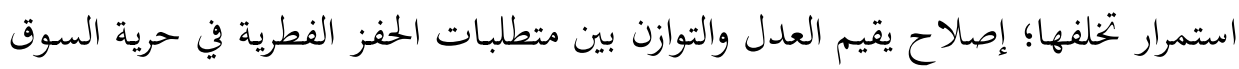

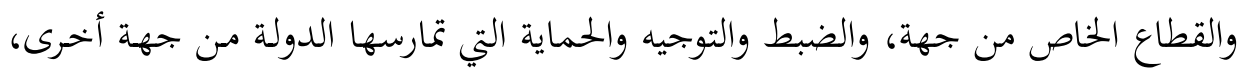


ويبني ثقافة المحتمع المنتج، ويقلص مس سلبيات الثقافة الاستهاكية، ويقيم التوازن في برامج التنمية الزراعية والصناعية والخدمات والتكنولوجيا الملائمة والمتقدمة، وما يلزم ذلك ولك كله من بنى تحتية في الطرق والأدوات والإدارة والمؤسسات.

هذه أمثلة على الآمال المنشودة التي تأمل الشعوب أن تتحقق نتيجة لما جرى ولا

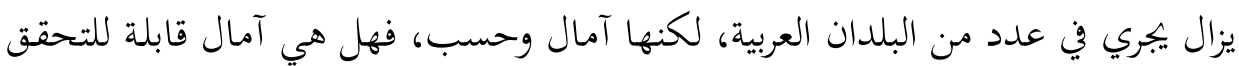

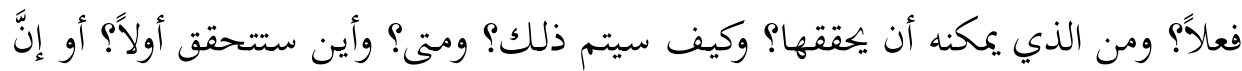
الشكوك والتخوفات التي تتنازع هذه الآمال هي أقرب إلى أن تحبط هذه الآمال وتطيح

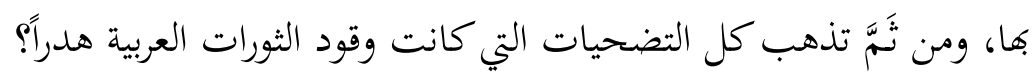
إلى أي درجــة يمكـن للآمـال والطموحـات أن تكـون عوامـل تفــاؤل تحـدد إمكانيـة

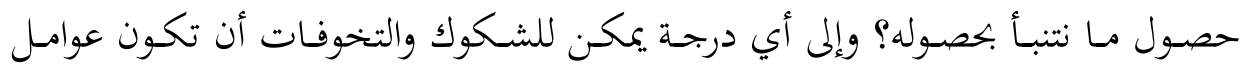

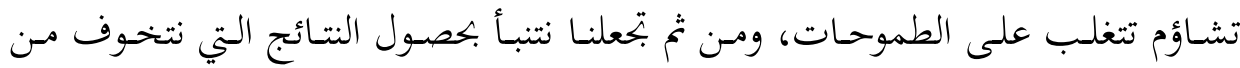
حصولما؟

ثالثاً: احتمالات وتوقعات هناك أمور تشير الأحداث الجارية الآن إلى احتمال كبير في ظهورهـا على الأقل في

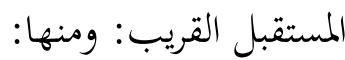
ا ـ في مسألة الأمس والاستقرار : ليس مـ السهل أن تختفي في أي بحتمع عناصر

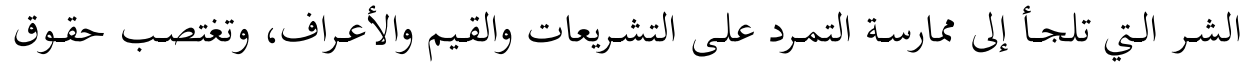

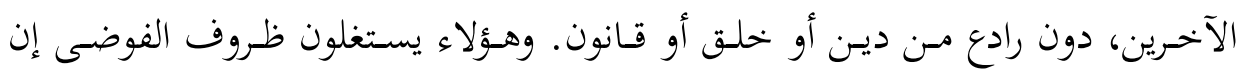

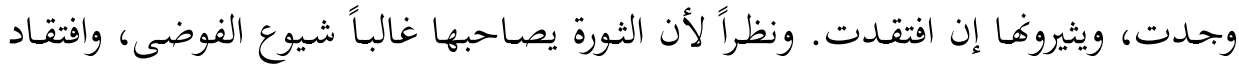

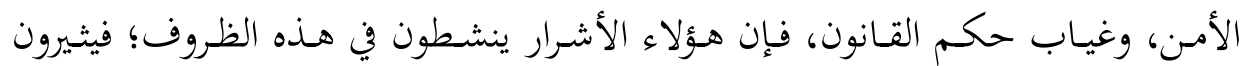
الفتن ويؤججون الصراعات، ويشجعون على حالة العصيان، ويقودون البسطاء من العامة في الاحتجاجات وقطع الطرق والتمرد، رافعين شعارات ظاهرهـا فيه الرحمة وباطنها مـن قبله العذاب! ويحتاج القضاء على هذه الحالة إلى بعض الوقت، وربما يستمر ذلك مـن 
سنتين إلى ثلاث سنوات، بعدها يتزايد وعي الناس بأهمية الأمن والاستقرار، ويزداد قلقهم

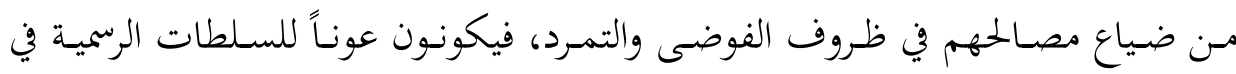

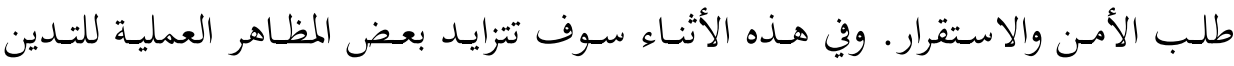

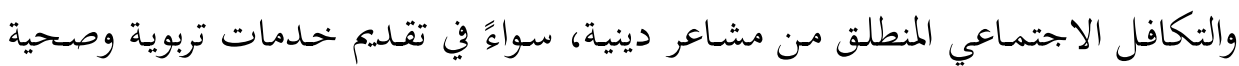
وثقافية، أو في المهرجانات الكبيرة التي سوف تقام في الاحتفالات بالمناسبات الدينية.

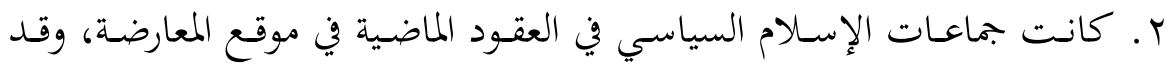

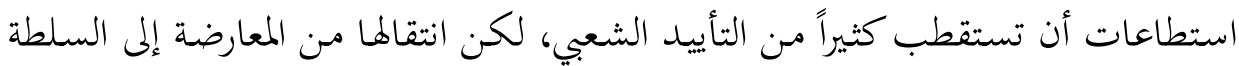

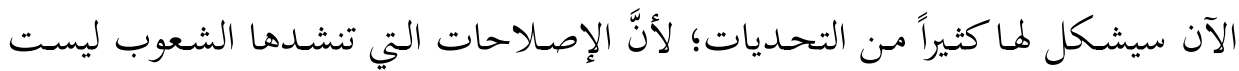

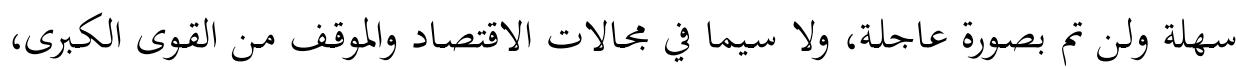

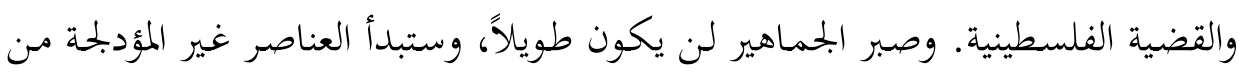

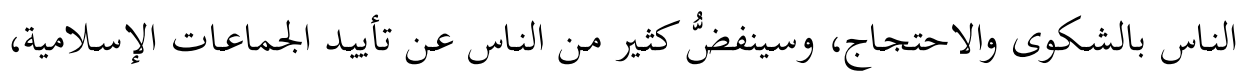

والأخطر من ذلك أن ثمة احتمالات بانتقال ذلك إلى الخلل في ظاهرة التدين نفسينها.

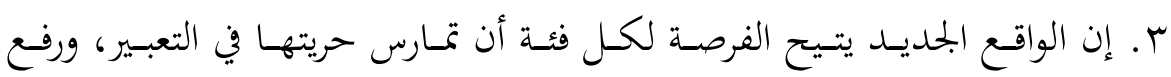

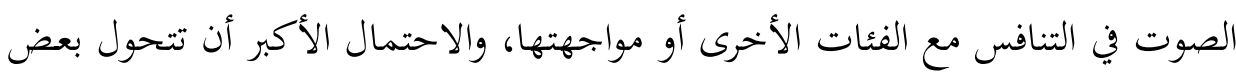

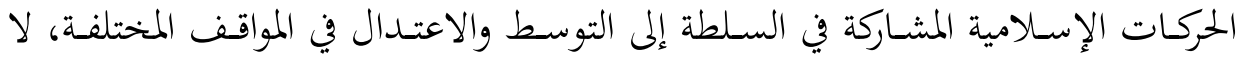
سيما في مسـائل السلوك الاجتمـاعي وقضايا الحريات وحقوق المواطنة. وسـوف تظهر

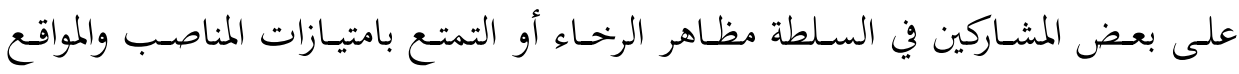

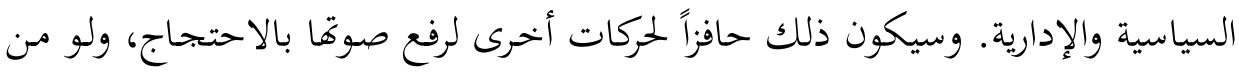

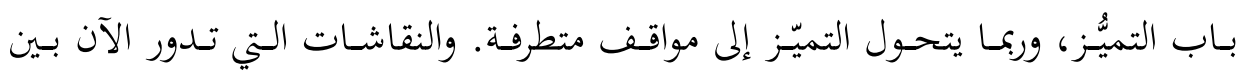

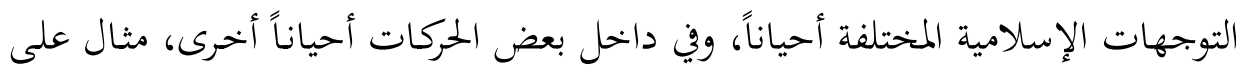
التنافس و (المزايدة) في بعض المواقف المعبرة عن التميّز في التدين.

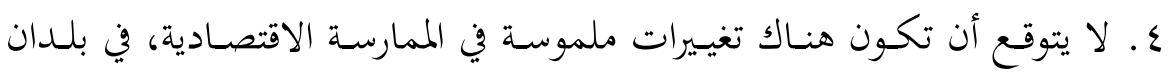
الثورات العربية؛ ذلك أن النظام الاشتراكي قد سقط غير مأسوف عليه، والنظام الرأسمالي عانى في ربع القرن الأخير من مظاهر كثيرة من الخلل، جعل الأزمات الاقتصادية الخانقة

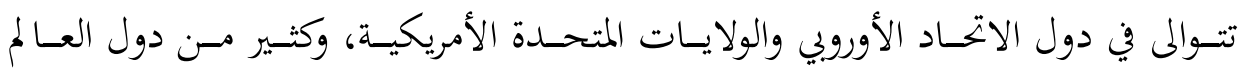
الأخرى. لذذلك سيكون هنـاك قدر كبير مـن الحـذر في اللجوء إلى تغييرات جوهريـة في 
الاقتصاد، وسوف يقتصر التغيير على إجراءات أكثر ضبطاً للشفافية ومحاولة الحـد من

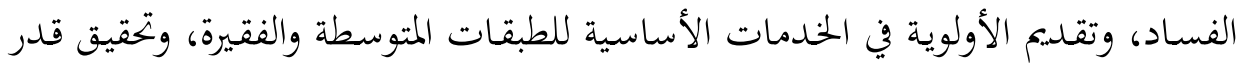

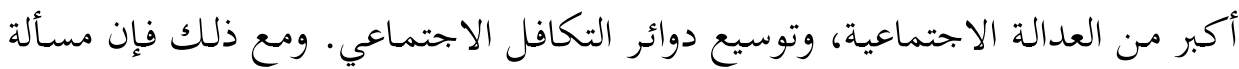
الإسلام في الاقتصاد لن تصل إلى إعادة صياغة فلسفة جديدة للنظام الاقتصادي وآلياته

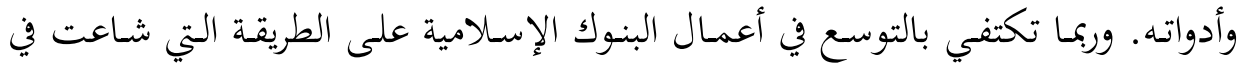

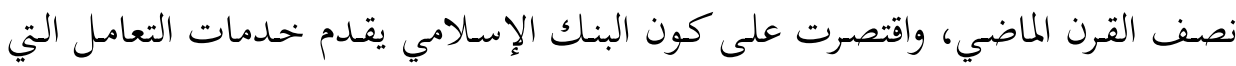

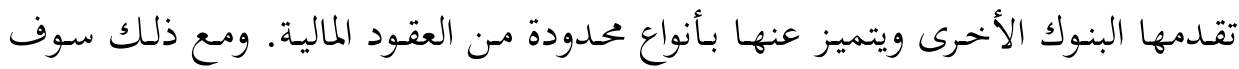

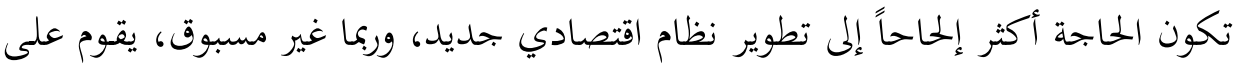
فلسفة اقتصادية جديدة، وسيتوجه هذا الإلحاح إلى المتخصصين في الفكر الاقتصادي من

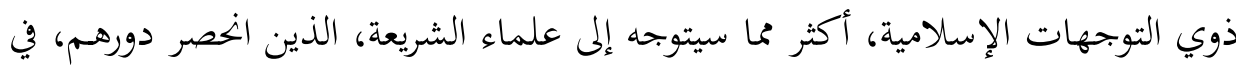

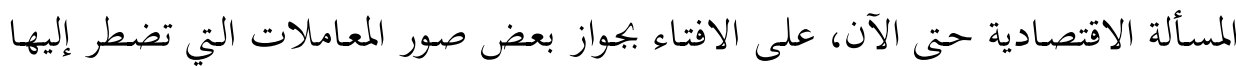
البنوك الإسلامية اضطراراً.

ه. يتوقـع أن يـزداد تقــارب القـوى الإسـلامية المعتدلـة مـن التوجهـات الليبراليـة في ممارساتها السياسية والاقتصادية، وفي قضايا الحريات الأساسية وحقوق المواطنة، بسبب لإبـ

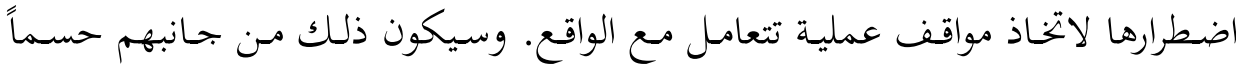
لبعض المسائل التي كانت الجهات الأخرى تعدها مناطق رمادية في مواقف الإسلاميين،

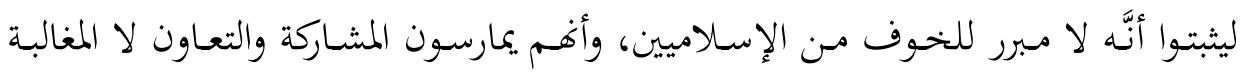

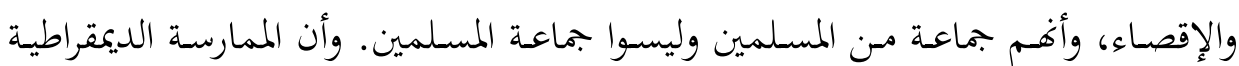
هي هدف استراتيجي لهم كما هو عند غيرهم، وليس تكتيكاً مؤقَّاً.

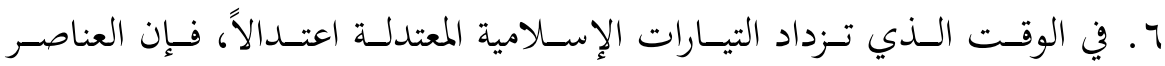

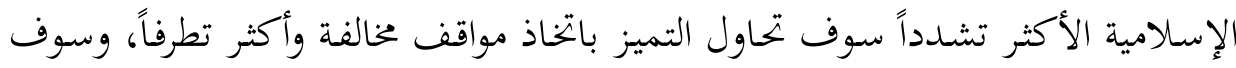

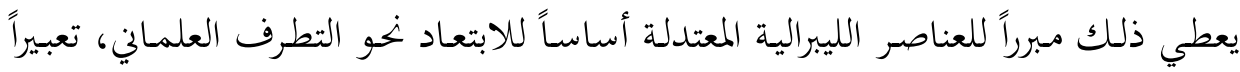

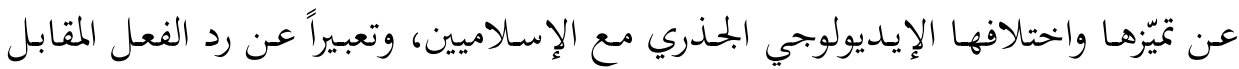

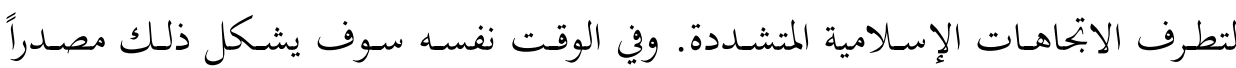

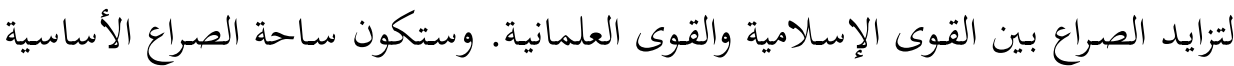
هي أجهزة الإعلام، التي سوف يبقى العلمانيون الأكثر خبرة والأعلى صوتاً فيها. 


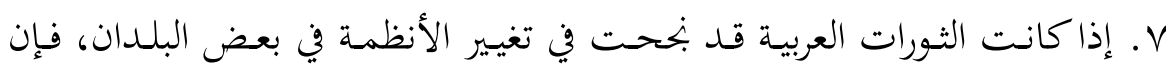

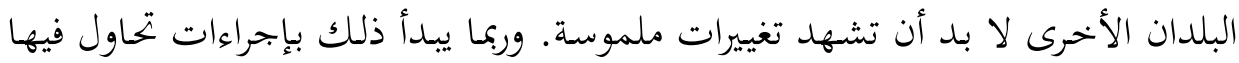

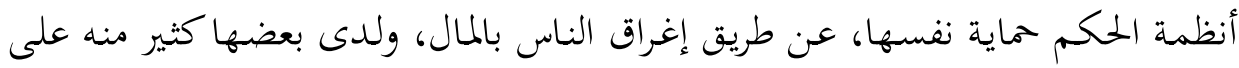

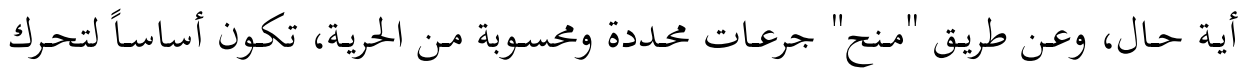

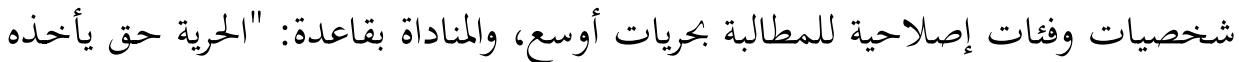

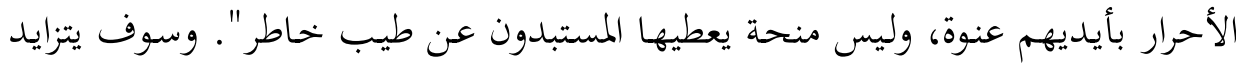

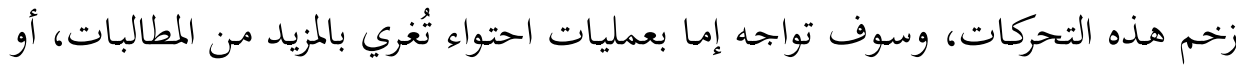

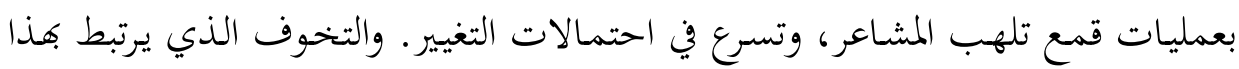

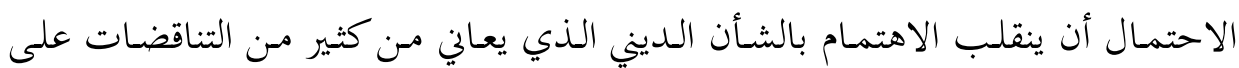

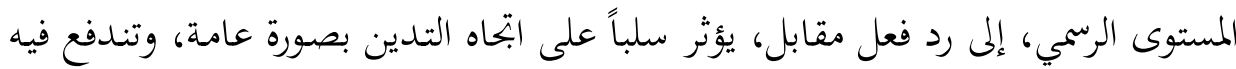

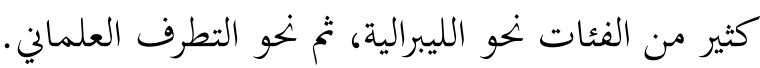

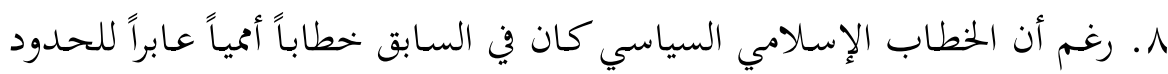

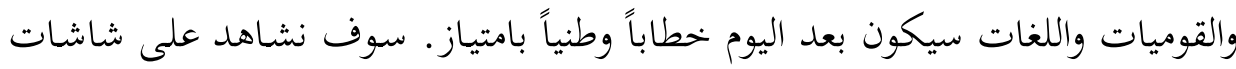

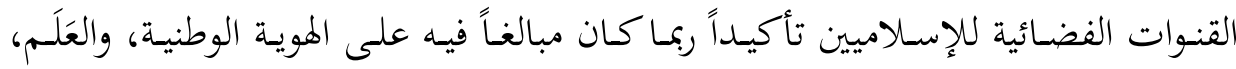

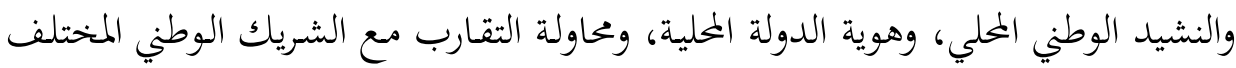

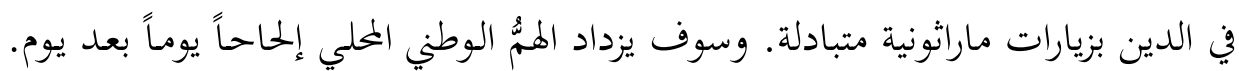

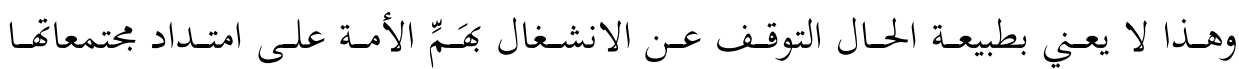

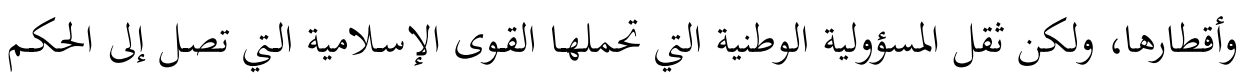

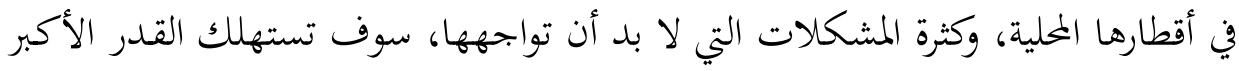
من الجهاد والوقت والإمكانات.

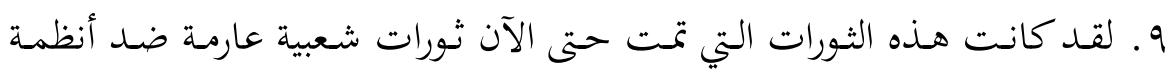

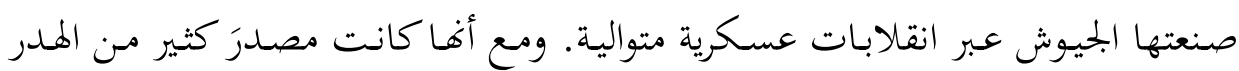

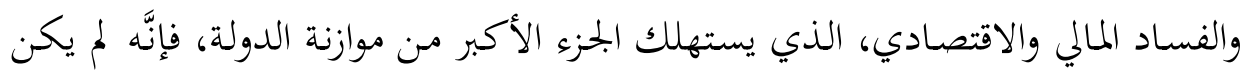

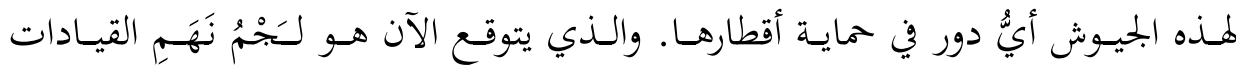

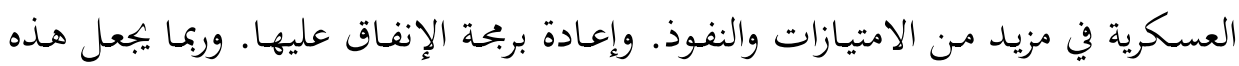

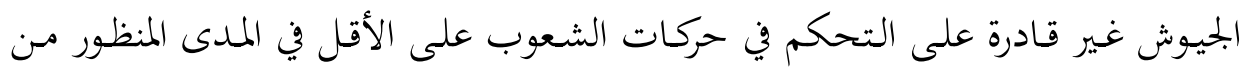
السنين القادمة. 
قد تبدو بحوث هذا العدد بعيدة عما يدور الآن في الساحة العربية، ولكنها ليست

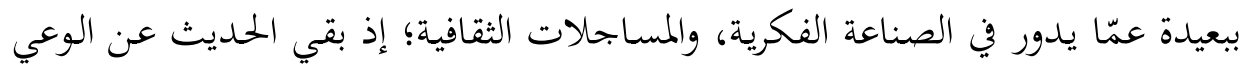

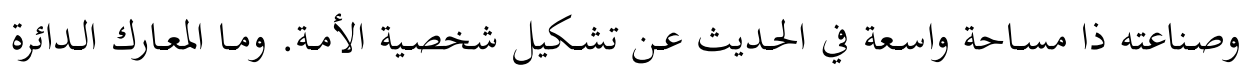
بين الإسلاميين والعلمانيين على المستوى السياسي إلا جزء من الجحدل الدائر حول هوية الأمة وماهيتها، فالصراع في عمقه صراع رؤية وفكر.

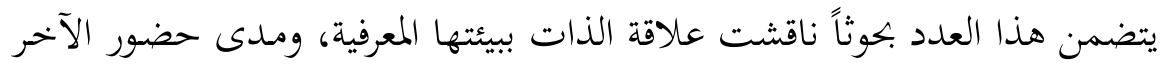

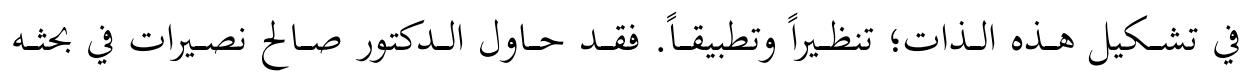

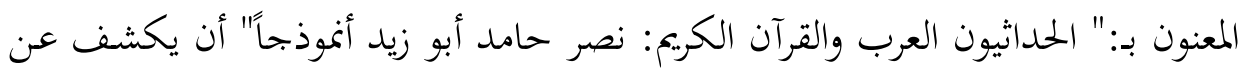

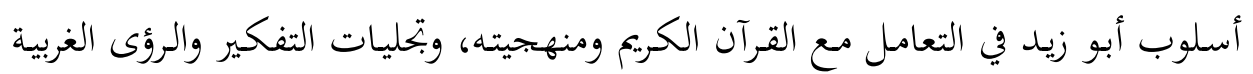
في فكر الحداثيين العرب في تعاملهم مع النصوص المقدسة.

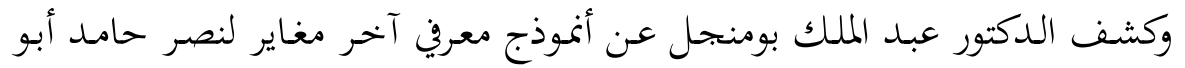

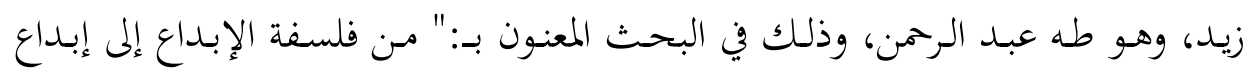

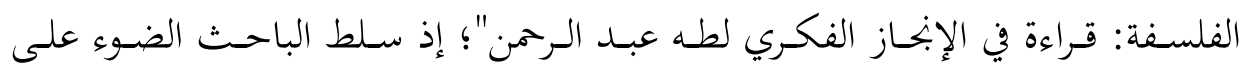

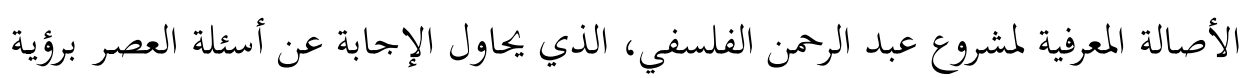
عربية إسلامية أصيلة. وسعى الدكتور الحاج دواق في بحثه الموسوم بـ:" التثاقف من مسلوبية الاحتواء إلى معقولية التثاقف" إلى الكشف عن المنطلقـات التوحيدية والرؤية القرآنية في تبيّن مفهوم

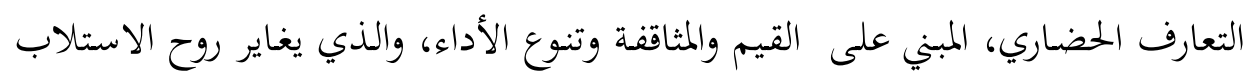
والاحتواء وإلغاء الآخر.

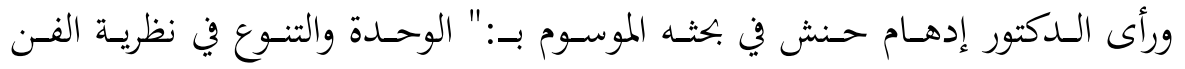
الإسلامي" أن التوحيد هو الجهوهر المعريي لنظرية الفن الإسلامي؛ فالتأصيل المعرين لنظرية

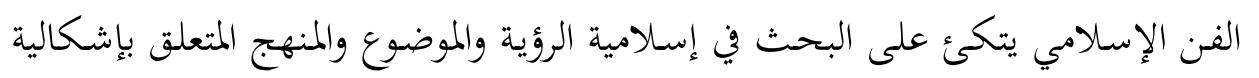

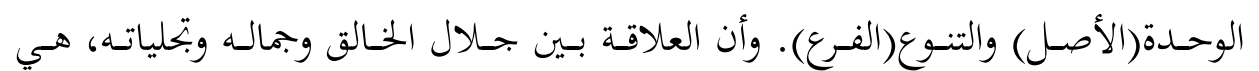

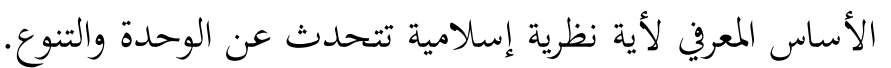
والله من وراء القصد 